\title{
Copy number changes at 8p11-12 predict adverse clinical outcome and chemo- and radiotherapy response in breast cancer
}

\author{
Cathy B. Moelans ${ }^{1}$, Caroline M. G. van Maldegem ${ }^{2}$, Elsken van der Wall ${ }^{3}$ and Paul \\ J. van Diest ${ }^{1}$ \\ ${ }^{1}$ Department of Pathology, University Medical Center Utrecht, Utrecht, The Netherlands \\ ${ }^{2}$ Department of Gynaecology, Albert Schweitzer Hospital, Dordrecht, The Netherlands \\ ${ }^{3}$ Cancer Center, University Medical Center Utrecht, Utrecht, The Netherlands \\ Correspondence to: Cathy B. Moelans, email: cmoelans@umcutrecht.nl \\ Keywords: breast cancer; loss; prognostic; predictive; $8 p$ \\ Received: November 30, $2017 \quad$ Accepted: March 12, $2018 \quad$ Published: March 30, 2018 \\ Copyright: Moelans et al. This is an open-access article distributed under the terms of the Creative Commons Attribution License \\ 3.0 (CC BY 3.0), which permits unrestricted use, distribution, and reproduction in any medium, provided the original author and \\ source are credited.
}

\section{ABSTRACT}

Purpose: The short arm of chromosome $8(8 p)$ is a frequent target of loss of heterozygosity (LOH) in cancer, and 8p LOH is commonly associated with a more aggressive tumor phenotype. The 8 p11-12 region is a recurrent breakpoint area characterized by a sharp decrease in gains/amplifications and increase in allelic loss towards 8pter. However, the clustering of genomic aberrations in this region, even in the absence of proximal amplifications or distal LOH, suggests that the 8p11-12 region could play a pivotal role in oncogenesis.

Results: Loss in the FGFR1 and ZNF703-containing 8p11 region was seen in $\mathbf{2 5} \%$ of patients, correlated with lower mRNA expression levels and independently predicted poor survival, particularly in systemic treatment-naïve patients and even without adjacent 8p12 loss. Amplification of FGFR1 at 8p11 and loss of DUSP26 and UNC5D, located in the 8p12 breakpoint region, independently predicted worse event free survival. Gains in the 8p12 region encompassing WRN, NRG1, DUSP26 and UNC5D, seen in $\mathbf{2 0 - 3 0 \%}$ of patients, were associated with higher mRNA expression and independently predicted chemotherapy sensitivity. Losses at 8p12 independently predicted radiotherapy resistance.

Material and methods: Multiplex ligation-dependent probe amplification was used to investigate copy number aberrations at 8p11-12 in 234 female breast cancers. Alterations were correlated with clinicopathologic characteristics, survival and response to therapy. Results were validated using public METABRIC data

Conclusion: Allelic loss and amplification in the 8p11-12 breakpoint region predict poor survival and chemo- and radiotherapy response. Assessment of 8p11-12 gene copy number status seems to augment existing prognostic and predictive tools.

\section{INTRODUCTION}

The short arm of chromosome $8(8 \mathrm{p})$ is a frequent target of loss of heterozygosity ( $\mathrm{LOH})$ in colorectal, hepatocellular, prostate, bladder, lung, ovarian as well as breast cancer [1-9]. Furthermore, $\mathrm{LOH}$ on $8 \mathrm{p}$ is more frequent in aggressive breast cancers with worse overall survival [10-14], in poorly differentiated and advanced stages of hepatocellular carcinoma [15], in advanced clinical stages of colorectal carcinomas [16], in bladder cancers of high grade and stage [17], and in prostate carcinomas with worse outcome $[18,19]$. This suggests 
that (synergistic) loss or inactivation of tumor suppressor genes on $8 \mathrm{p}$ plays a role in the progression of multiple cancer types.

To establish molecular drivers of $8 p$ loss, several studies have tried to pinpoint one or more regions of minimal deletion using either cell lines or human breast cancers $[5,12,13,20,21]$. The results have been inconsistent, with regions at 8p12,8p12-21, 8p22 and 8p22-23.3 being reported. Recently, Cai et al. pinpointed a region commonly affected by $8 p$ deletions using TCGA data, and subsequently examined the effect of a chromosome 8p 2-35 Mb targeted deletion, which was insufficient to transform MCF10A cells, but altered the fatty acid and ceramide metabolism leading to increased invasiveness and enhanced autophagy [14].

$\mathrm{LOH}$ of $8 \mathrm{p}$ is often but not always associated with amplification of the neighbouring 8p12-p11.23 region, containing FGFR1 and ZNF703. Concomitant break and amplification are likely to result from the breakage-fusion-bridge mechanism [22]. However, the clustering of breakpoints, even in the absence of proximal amplifications or distal deletions, suggests that the $8 \mathrm{p} 12$ region is sensitive to breakages and could play a pivotal role in oncogenesis via inactivation of one or several tumor suppressor genes, and/or activation of one or more oncogenes. Adding to the complexity, the nature of specific driver genes and the type of copy number alteration in this breakpoint region may be context dependent. Here, we explore METABRIC data and confirm that $8 \mathrm{p} \mathrm{LOH}$ is a frequent phenomenon in poor-prognosis breast cancer, with a sharp increase in the frequency of copy number loss between ZNF703 (20\% loss, 26\% gain/amplification) and WRN (39\% loss, $9 \%$ gain/amplification) at 8 p12. Subsequently, we show in a large series of breast cancer patients that allelic loss and amplification in the 8p11-12 breakpoint region predict poor survival and chemoradiotherapy response. Regardless of why cancer cells select for amplifications in some settings and copy number loss in others, these results should increase consideration of the prognostic and predictive potential of copy number aberrations in this region.

\section{RESULTS}

\section{METABRIC breakpoint identification}

Supplementary Figure 1 depicts a heatmap of putative copy number calls on chromosome $8 \mathrm{p}$ observed in METABRIC ( $\mathrm{n}=2173$ informative cases). In 94\% of cases, the copy number status of FGFR1 and ZNF703 was similar. However, a very strong putative breakpoint was observed in a more distal region between $Z N F 703$ (37553269 bp from pter) and DUSP26 (33448851 bp from pter), where DUSP26 was gained or amplified in $14 \%$ of cases (versus $26 \%$ of cases for ZNF703) and lost in $34 \%$ of cases (versus $20 \%$ for $Z N F 703$ ). This region contains two other genes, KCNU1 (36641842 bp from pter) and UNC5D (35092975 bp from pter). A putative breakpoint between ZNF703 and KCNU1 was observed in 155/2173 cases $(7 \%)$ while putative breakpoints between $K C N U 1$ and UNC5D and between UNC5D and DUSP26 were present in 204/2173 (9.4\%) and 197/2173 (9.1\%) cases. Breakpoints between DUSP26 and neighbouring gene $R N F 122$ were however much less frequent $(3 / 2173 ; 0.1 \%)$. Between NRG1 and $W R N$, another weaker breakpoint was observed, with $36 \%$ and $39 \%$ loss, and $13 \%$ and $9 \%$ gain/ amplification of $N R G 1$ and $W R N$, respectively.

\section{8p11-12 copy number alterations by MLPA}

Table 1 shows the frequency of allelic loss, copy number increase and high-level amplification observed in the investigated genes and genomic subregions and Table 2 shows the significant associations of these copy number alterations with pathological characteristics. Raw chromosome 8p MLPA and corresponding clinical/ pathological data are provided in Supplementary Table 4. Overall, regardless of the genomic sub-region, copy number increase on the short arm of chromosome 8 was associated with high grade $(\mathrm{p}=0.037)$ and high mitotic activity $(p=0.011)$. Copy number increase and high level amplification were most frequently observed in luminal B-like tumors ( $\mathrm{p}=0.017$ and $\mathrm{p}=0.003$ respectively; $68 \%$ demonstrated a copy number increase at $8 \mathrm{p}$ ). The presence of an allelic loss on the short arm of chromosome 8 was associated with ductal histology $(\mathrm{p}=0.027), \mathrm{PR}$ negativity $(p=0.031)$, high grade $(p=0.008)$ and high mitotic activity $(\mathrm{p}=0.003)$. Allelic loss at $8 \mathrm{p}$ was most frequent in nonluminal A-like ( $\mathrm{p}=0.003 ; 32 \%$ in luminal A-like) tumors and tended to be more prevalent in luminal B-like $(p=0.053 ; 57 \%)$ and triple negative $(p=0.065 ; 61 \%)$ tumors presenting at older age $(\mathrm{p}=0.057)$.

Copy number increase of at least 1 of the 4 genes in the $8 \mathrm{p} 12$ region (WRN, NRG1, DUSP26 and/or UNC5D) was associated with HER2 negativity $(\mathrm{p}=0.014)$. Copy number increase, especially high-level amplification of at least 1 of the 3 genes in the 8 p11 region (ZNF703, FGFR1 and/or FNTA) was predominantly seen in luminal B-like tumors $(\mathrm{p}=0.016$ and $\mathrm{p}=0.005$, respectively) and tumors with high mitotic counts $(p=0.039$ and $p=0.016$, respectively). Allelic loss of at least 1 gene in the $8 \mathrm{p} 12$ region was more prevalent in luminal B-like tumors $(\mathrm{p}=0.040)$ and tumors diagnosed at older age $(\mathrm{p}=0.027)$. Allelic loss of the $8 \mathrm{p} 11$ genomic subregion was associated with ER and PR negativity $(p=0.015$ and $p=0.011$, respectively), high mitotic activity $(\mathrm{p}=0.034)$, a nonluminal A-like subtype $(\mathrm{p}=0.013)$ and triple negativity $(p=0.013 ; 45 \%$ demonstrated allelic loss at the $8 \mathrm{p} 11$ region). Supplementary Figure 2 depicts the frequencies of $8 \mathrm{p}$ regional copy number alterations in each molecular breast cancer subtype. 
Table 1: Frequency of allelic loss, copy number increase (gain or amplification) and amplification (cut-off 2.0) by MLPA

\begin{tabular}{|c|c|c|c|c|c|c|c|}
\hline Gene & $\begin{array}{c}\text { Ensembl } \\
\text { cytogenetic band }\end{array}$ & $\begin{array}{l}\text { Distance from } \\
\text { pter (Mbp) }\end{array}$ & $\begin{array}{c}\text { Cut-off } \\
\text { Loss }\end{array}$ & $\begin{array}{c}\text { Cut-off Gain/ } \\
\text { Amp }\end{array}$ & $\%$ Loss & $\begin{array}{c}\text { \% Gain/ } \\
\text { Amp }\end{array}$ & $\%$ Amp \\
\hline$W R N$ & $8 \mathrm{p} 12$ & 31.0 & 0.82 & 1.14 & 10 & 8 & 1 \\
\hline$N R G 1$ & $8 \mathrm{p} 12$ & 31.6 & 0.81 & 1.17 & 9 & 10 & 1 \\
\hline DUSP26 & $8 \mathrm{p} 12$ & 33.6 & 0.80 & 1.31 & 16 & 10 & 1 \\
\hline UNC5D & $8 \mathrm{p} 12$ & 35.2 & 0.78 & 1.43 & 13 & 12 & 3 \\
\hline ZNF703 & $8 \mathrm{p} 11.23$ & 37.7 & 0.71 & 1.37 & 9 & 31 & 15 \\
\hline FGFR1 & $8 p 11.23$ & 38.4 & 0.82 & 1.16 & 12 & 19 & 7 \\
\hline FNTA & $8 \mathrm{p} 11.21$ & 43.0 & 0.77 & 1.36 & 5 & 19 & 3 \\
\hline PRKDC & $8 \mathrm{q} 11.21$ & 47.8 & 0.75 & 1.25 & 1 & 26 & 2 \\
\hline $8 p 12$ & $\geq 1$ of 4 genes & - & - & - & 36 & 31 & 4 \\
\hline $8 p 12$ only & $\geq 1$ of 4 genes & - & - & - & 6 & 9 & 0 \\
\hline transition & $\geq 1$ of 3 genes & - & - & - & 33 & 21 & 4 \\
\hline transition only & $\geq 1$ of 3 & - & - & - & 9 & 5 & 0 \\
\hline $8 p 11$ & $\geq 1$ of 3 genes & - & - & - & 26 & 42 & 16 \\
\hline 8p11 only & $\geq 1$ of 3 genes & - & - & - & 7 & 8 & 5 \\
\hline $8 p 11-12$ & $\geq 1$ of 7 genes & - & - & - & 44 & 52 & 17 \\
\hline
\end{tabular}

Cut-offs for loss and gain/amplification were determined per gene, based on the minimum and maximum ratio values of normal breast tissue.

Transition $=$ region including NRG1, DUSP26 and UNC5D.

Only $=$ without adjacent loss or gain/amp.

\section{FGFR1 MLPA versus FISH}

Paired MLPA-FISH data were available for 179 tumors. As illustrated in Supplementary Figure 3, $17 / 20(85 \%)$ cases with loss by MLPA showed a loss by FISH as well, and 27/28 (96\%) cases showing gain or amplification by MLPA were also gained/amplified by FISH. 114/131 (87\%) cases with no alterations by MLPA showed normal FISH copy numbers. The Pearson correlation between MLPA and FISH was strong $(\mathrm{r}=0.855, \mathrm{p}<0.05)$. In $50 \%$ of cases, CEP8 was increased when FGFR1 copy number was increased and in 33\% of cases, CEP8 demonstrated copy number loss when FGFR1 showed loss, suggesting that $8 \mathrm{p} 11$ loss or gain/ amp is not always the result of chromosome 8 polysomy or monosomy. All cases with CEP8 loss also showed FGFR1 loss, and the majority (67\%) of CEP8 gained cases also demonstrated FGFR 1 copy number increase.

\section{Chromosome 8p copy number alterations predict worse prognosis}

Table 3 summarizes unadjusted log-rank p-values and adjusted hazard ratios (HR) of $8 p$ genes and (sub) regions significantly associated with overall (OS) and event free (EFS) survival. Copy number increase (gain or amplification) of DUSP26, and allelic loss of DUSP 26 and UNC5D individually predicted OS. Overall, the presence of $\geq 1$ gain/amplification or $\geq 1$ loss within the 8p11-12 region was indicative of a worse OS in univariable analysis. As for the genomic subregions, gain/ amplification or loss at 8p11, even without adjacent 8p12 copy number aberrations (Figure 1), predicted poor OS. After correction for age, stage, intrinsic subtype, tumor size, ER/PR/HER2 status, grade, MAI, and LN status, loss within the $8 \mathrm{p} 11$ region, especially without adjacent $8 \mathrm{p} 12$ loss, was an independent prognostic variable for OS $(\mathrm{p}=0.022 ;$ HR 3.3). Gain/amplification in the $8 \mathrm{p} 11$ region also independently predicted poor OS. The presence of at least one high-level amplification at $8 \mathrm{p}$ was indicative for worse EFS in multivariable analysis $(\mathrm{p}=0.038)$. Only in ER-positive tumors, allelic loss at the $8 \mathrm{p} 12$ subregion was associated with worse EFS ( $p=0.041)$. Even in the generally less aggressive luminal A-like tumors, $8 \mathrm{p} 12$ loss or gain/amplification predicted worse EFS ( $\mathrm{p}=0.045$ and $\mathrm{p}=0.004$, respectively). Individually, $D U S P 26$ and $U N C 5 D$ copy number loss (Figure 1) and ZNF703 and FGFR1 amplification independently predicted worse EFS. 
Table 2: The association of $8 p$ copy number alterations with clinical/pathological characteristics

\begin{tabular}{|c|c|c|c|c|c|}
\hline $\begin{array}{l}\text { Loss vs } \\
\text { Neutral }\end{array}$ & WRN NRG1 & DUSP26 & UNC5D & 8p12 & ZNF703 \\
\hline Age & $\begin{array}{c}>50 \\
(0.043)\end{array}$ & $\begin{array}{c}>50 \\
(0.002)\end{array}$ & $\begin{array}{c}>50 \\
(0.047)\end{array}$ & $\begin{array}{c}>50 \\
(0.027)\end{array}$ & $>50(0.048)$ \\
\hline \multicolumn{6}{|l|}{$\mathbf{p N}$} \\
\hline pT & & & & & \\
\hline
\end{tabular}

Grade

Histological

subtype

MAI

$$
\begin{array}{rrr} 
& & \text { high }(0.034) \\
\operatorname{neg}(\mathbf{0 . 0 3 6}) & \operatorname{neg}(0.015) \\
\operatorname{neg}(\mathbf{0 . 0 3 8}) & \operatorname{neg}(\mathbf{0 . 0 1 7}) & \operatorname{neg}(0.011)
\end{array}
$$

ER

PR

\section{HER2}

LumA-like no $(0.042) \quad$ no $(p=0.013)$

LumB-like yes (0.040)

TN yes $(0.044)$

HER2-like

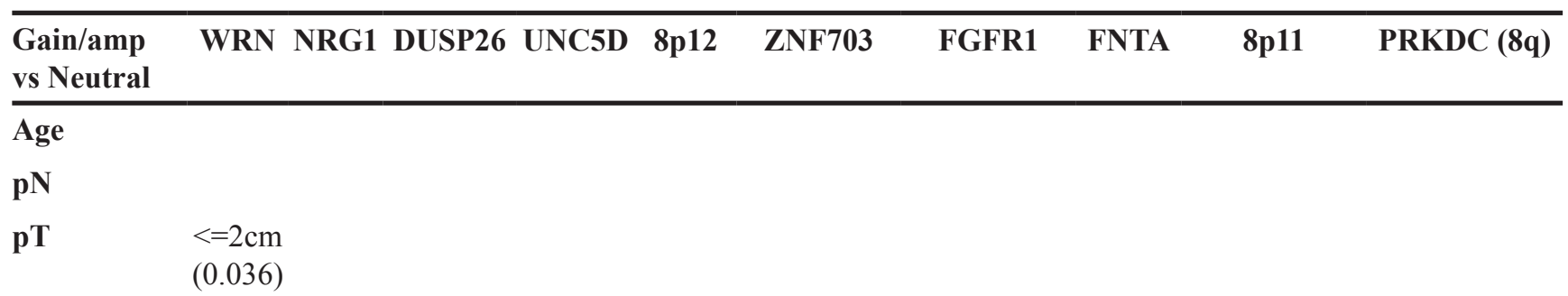

Grade

Histological subtype

MAI

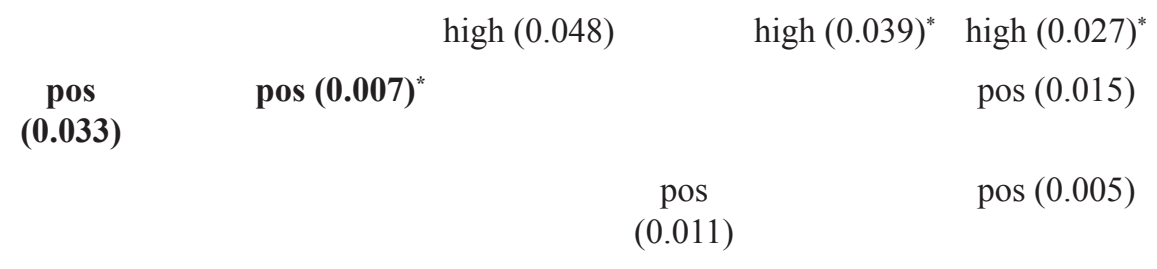

HER2

$$
\begin{gathered}
\text { neg } \\
(0.014)
\end{gathered}
$$

LumA-like

LumB-like

$$
\begin{gathered}
\text { yes } \\
(\mathbf{0 . 0 1 8})
\end{gathered}
$$

yes $(0.026)^{*} \quad$ yes $(0.002)$

yes $(0.016)^{*} \quad$ yes $(0.008)$

TN

no (0.036)

\section{HER2-like}

Bold indicates a similar association in METABRIC. Gain/amp values with asterisk $\left(^{*}\right)$ indicate associations also seen at MLPA cut-off 2.0 (high-level amplification). 
Table 3: Unadjusted log-rank p-values and adjusted hazard ratios (HR) of 8p genes and (sub)regions significantly associated with overall (OS) and event free (EFS) survival

\begin{tabular}{|c|c|c|c|c|}
\hline \multirow{2}{*}{$\begin{array}{l}\text { OS } \\
\text { Gain/amplification }\end{array}$} & \multirow[t]{2}{*}{ Univariate } & \multicolumn{3}{|c|}{ Cox proportional hazards } \\
\hline & & p-value & $H R$ & $95 \% C I$ \\
\hline DUSP26 & 0.017 & 0.012 (cat)/0.043 (avg) & $2.913 / 2.891$ & $\begin{array}{c}1.271- \\
6.678 / 1.034- \\
8.086\end{array}$ \\
\hline $8 p 11$ & 0.014 & 0.097 & 1.848 & $0.895-3.816$ \\
\hline 8p11 only & 0.033 & - & - & - \\
\hline $8 p 11-12$ & 0.043 & - & - & - \\
\hline Amplification & & p-value & $H R$ & $95 \% C I$ \\
\hline ZNF703 & - & - & - & - \\
\hline FGFR1 & - & - & - & - \\
\hline $8 p 11-12$ & - & - & - & - \\
\hline Loss & & p-value & $H R$ & $95 \% C I$ \\
\hline DUSP26 & - & - & - & - \\
\hline$U N C 5 D$ & - & - & - & - \\
\hline $8 p 11$ & 0.012 & 0.065 & 2.092 & $0.955-4.585$ \\
\hline $8 p 11$ only & 0.010 & 0.022 & 3.323 & $1.189-9.284$ \\
\hline $8 p 11-12$ & 0.017 & 0.084 & 2.045 & $0.908-4.606$ \\
\hline EFS & Univariate & \multicolumn{3}{|c|}{ Cox proportional hazards ${ }^{* *}$} \\
\hline Gain/amplification & & p-value & $H R$ & $95 \% C I$ \\
\hline DUSP26 & - & - & - & - \\
\hline $8 p 11$ & - & - & - & - \\
\hline 8p11 only & - & - & - & - \\
\hline $8 p 11-12$ & - & - & - & - \\
\hline Amplification & & p-value & $H R$ & $95 \% C I$ \\
\hline ZNF703 & - & 0.036 & 3.198 & $1.081-9.462$ \\
\hline FGFR1 & - & 0.010 & 10.809 & $1.767-66.118$ \\
\hline $8 p 11-12$ & - & 0.038 & 4.721 & $1.090-20.440$ \\
\hline Loss & & p-value & $H R$ & $95 \% C I$ \\
\hline DUSP26 & 0.041 & 0.046 (cat)/0.089 (cont) & $2.340 / 0.388$ & $\begin{array}{c}1.017- \\
5.383 / 0.130- \\
1.157\end{array}$ \\
\hline$U N C 5 D$ & 0.013 & 0.104 (cont) & 0.364 & $0.108-1.232$ \\
\hline $8 p 11$ & - & - & - & - \\
\hline 8p11 only & - & - & - & - \\
\hline $8 p 11-12$ & - & - & - & - \\
\hline
\end{tabular}

Comparison versus neutral copy number.

*adjusted for age (cont), stage, intrinsic subtype, tumor size (cont), ER/PR, Grade, MAI (cont), LN status.

**adjusted for age (cont), intrinsic subtype, tumor size (cont), ER/PR/HER2, Grade, MAI, LN status.

cont $=$ as continuous variable (raw MLPA ratio); cat = as categorical variable (cut-off based on normal tissue). 


\section{Chromosome 8p copy number alterations predict response to therapy}

Supplementary Table 5 summarizes adjusted hazard ratios (HR) of $8 \mathrm{p}$ genes and (sub)regions significantly associated with EFS in different treatment categories. In CT-naïve patients, Cox-regression analysis indicated a better EFS if $8 \mathrm{p} 11$ or $8 \mathrm{p} 11-12$ losses $(\mathrm{p}=0.035$ and $\mathrm{p}=0.02$, respectively) or gains/amplifications $(\mathrm{p}=0.004$ and $\mathrm{p}=0.004$, respectively) were present, and in case of NRG1 loss ( $\mathrm{p}=0.042)$. In CT-treated patients, however, multivariable analysis indicated a worse EFS if $8 \mathrm{p} 12$ or $8 \mathrm{p} 11-12$ losses were present $(\mathrm{p}=0.002$ and $\mathrm{p}=0.082$, respectively), and better EFS when 8p12 gains were present $(\mathrm{p}=0.009)$, suggesting an association between $8 \mathrm{p}$ copy number alterations and CT response. Also individually, loss of $W R N(\mathrm{p}=0.001), N R G 1 \quad(\mathrm{p}<0.001)$, DUSP26 $\quad(\mathrm{p}<0.001), \quad$ UNC5D $\quad(\mathrm{p}<0.001), \quad$ ZNF703 $(\mathrm{p}<0.001)$ or $F N T A(\mathrm{p}=0.001)$ and copy number increase of ZNF703 ( $\mathrm{p}=0.052$ gain/amp and $\mathrm{p}=0.011 \mathrm{amp}), F G F R 1$ $(\mathrm{p}=0.038$ gain/amp and $\mathrm{p}=0.003 \mathrm{amp})$ and $F N T A(\mathrm{p}=0.046$ amp) independently predicted worse EFS in patients receiving $\mathrm{CT}$.

In HT-naïve patients, multivariable analysis indicated worse EFS when tumors showed 8p11 $(\mathrm{p}=0.037), 8 \mathrm{p} 12(\mathrm{p}=0.053)$ or $8 \mathrm{p} 11-12(\mathrm{p}=0.026)$ loss, and better EFS for tumors with $8 \mathrm{p} 12$ gains $(\mathrm{p}=0.037)$. Individually, $W R N(\mathrm{p}=0.011), N R G 1(\mathrm{p}=0.006), D U S P 26$ $(\mathrm{p}=0.001)$ and $U N C 5 D(\mathrm{p}=0.001)$ copy number decrease independently predicted worse EFS in HT-naïve patients. In patients receiving $\mathrm{HT}$, these associations were no longer apparent but ZNF703, DUSP26 and 8p11 amplification independently predicted better EFS. In patients receiving RT, 8p12 loss ( $\mathrm{p}=0.034)$ and DUSP 26 copy number loss $(\mathrm{p}=0.053)$ independently predicted worse EFS.

\section{METABRIC confirms prognostic and predictive value of $8 p$ copy number alterations}

Supplementary Table 6 shows METABRIC copy number variation frequencies of all chromosome 8 genes interrogated by MLPA. Supplementary Table 7 shows the association between chromosome 8 copy number variations by METABRIC and ER/PR/HER2 status, surrogate intrinsic subtype, tumor size, grade, stage and mutation load. In METABRIC tumors, allelic loss of at least one of the interrogated genes was significantly correlated with ER negativity $(\mathrm{p}=0.000018 ; 57 \%$ of ER- tumors), PR negativity ( $\mathrm{p}<0.0000001 ; 57 \%)$, HER 2 positivity $(\mathrm{p}<0.0000001 ; 69 \%)$ and a non-luminal A-like $(\mathrm{p}<0.0000001 ; 60 \%)$, luminal B-like $(\mathrm{p}<0.0000001 ; 61 \%)$ or HER2-driven $(\mathrm{p}<0.0000001 ; 67 \%)$ surrogate intrinsic subtype. Tumors were larger $(\mathrm{p}=0.001 ; 51 \%)$ and of higher stage $(\mathrm{p}=0.007 ; 61 \%)$ and grade $(\mathrm{p}<0.0000001 ; 62 \%)$ compared to copy number neutral tumors. There was no association with age. In the METABRIC dataset, copy number increase of at least one of the 7 interrogated genes was significantly associated with older age $(\mathrm{p}=0.048)$ and, similar to copy number losses in this region, with large tumor size $(\mathrm{p}=0.014)$, high grade $(\mathrm{p}<0.0000001)$ and stage $(\mathrm{p}=0.004), P R$ negativity $(\mathrm{p}=0.0001)$, HER 2 positivity $(p=0.005)$, non-luminal A-like $(p<0.0000001)$, luminal B-like $(p<0.0000001)$ and HER2-driven $(p=0.014)$ surrogate intrinsic subtype. Overall, upon comparison of our data with METABRIC, we were able to confirm the positive association between chromosome $8 \mathrm{p} 11-12$ loss, PR negativity and high grade, and the negative association between these losses (particularly ZNF703 loss) and the luminal A subtype. Furthermore, METABRIC confirmed the association between 8p11-12 gain, high grade and the luminal B-like subtype.

In METABRIC, copy number loss at 8p11-12, $8 \mathrm{p} 11,8 \mathrm{p} 12$ and $8 \mathrm{p}$ LOH were correlated with worse disease free survival (DFS; all $\mathrm{p}<0.000001$ ). Also, patients showing $8 \mathrm{p} 11$ loss without adjacent $8 \mathrm{p} 12$ loss showed a significantly worse DFS compared to patients where both regions were copy number neutral $(\mathrm{p}=0.028$; Figure 2). Individually, the loss of all interrogated genes correlated with worse DFS (all $\mathrm{p}<0.000001$ except FNTA $\mathrm{p}=0.000001$ and $P R K D C \mathrm{p}=0.0002)$. Amplification of 8p11-12, 8p11 and to a lesser extent 8p12 correlated with worse DFS too $(\mathrm{p}=0.00001, \mathrm{p}=0.00001$ and $\mathrm{p}=0.011$, respectively). Individually, DUSP26, UNC5D, ZNF703, FGFR1, FNTA and PRKDC amplifications predicted worse DFS ( $\mathrm{p}=0.021, \mathrm{p}=0.001, \mathrm{p}=0.003, \mathrm{p}=0.00006$, $\mathrm{p}=0.002$ and $\mathrm{p}=0.001$, respectively). The correlation between copy number loss or gain/amp and worse survival was most prominent in ER positive HER2 negative tumors with high proliferation. Also within PAM50classified luminal A tumors, 8p12 loss ( $\mathrm{p}=0.007), 8 \mathrm{p} 11$ loss $(\mathrm{p}=0.012)$ and $8 \mathrm{p} 11-12$ loss $(\mathrm{p}=0.005)$ predicted worse DFS. After correction for age, tumor size, stage and grade, ER/PR/HER2 status and 3-gene classifier subtype, the loss of $W R N(\mathrm{p}=0.053$; HR 1.2), DUSP26 ( $\mathrm{p}=0.022$; HR 1.3), UNC5D ( $\mathrm{p}=0.026$; HR 1.3), ZNF703 ( $\mathrm{p}=0.026$; HR 1.3) and FGFRI ( $\mathrm{p}=0.002$; HR 1.5) still predicted worse DFS. Of these 5 genes entered simultaneously in the model, DUSP26 ( $\mathrm{p}=0.014$; HR 1.37; 95\% CI 1.07-1.77) remained as best DFS predictor. Overall a loss within the $8 \mathrm{p} 11$ ( $\mathrm{p}=0.006$; HR 1.40; 95\% CI 1.1-1.77) but not the $8 \mathrm{p} 12$ subregion independently predicted worse survival. Amplification at $8 \mathrm{p} 11-12(\mathrm{p}=0.047$; HR $1.30 ; 95 \% \mathrm{CI}$ 1.00-1.69), 8p11 ( $\mathrm{p}=0.033$ HR 1.32; 95\% CI 1.02-1.70) and FGFRI ( $\mathrm{p}=0.007$ HR $1.47 ; 95 \%$ CI 1.11-1.94) also remained in the model when corrected for other prognostic variables. As compared to our dataset, METABRIC thus confirmed 8p11 loss, even without adjacent 8p12 loss, DUSP26 loss, UNC5D loss, FGFR1 amplification and amplification at 8p11-12 as independent predictors of worse survival.

Supplementary Table 8 summarizes adjusted HR of $8 \mathrm{p}$ genes and (sub) regions significantly associated with 
DFS in different treatment categories of the METABRIC dataset. 8p12 gains independently predicted better DFS in CT-treated patients ( $\mathrm{p}=0.040$; HR 0.58; 95\% CI 0.34-0.98) but not in CT-naïve patients, suggesting a correlation with chemotherapy sensitivity. FNTA amplifications predicted worse DFS in CT-treated patients $(\mathrm{p}=0.047)$ but not in CTnaïve patients, suggesting a correlation with CT resistance. FGFR1 losses independently predicted worse DFS in RTtreated patients $(\mathrm{p}=0.033$; HR $1.39 ; 95 \%$ CI 1.03-1.88) but not in RT-naïve patients, suggesting a correlation with radiotherapy resistance. In addition, a loss of at least 2 genes of NRG1,DUSP26 and UNC5D predicted RT resistance as well ( $\mathrm{p}=0.02$; HR 1.35; 95\% CI 1.05-1.73).
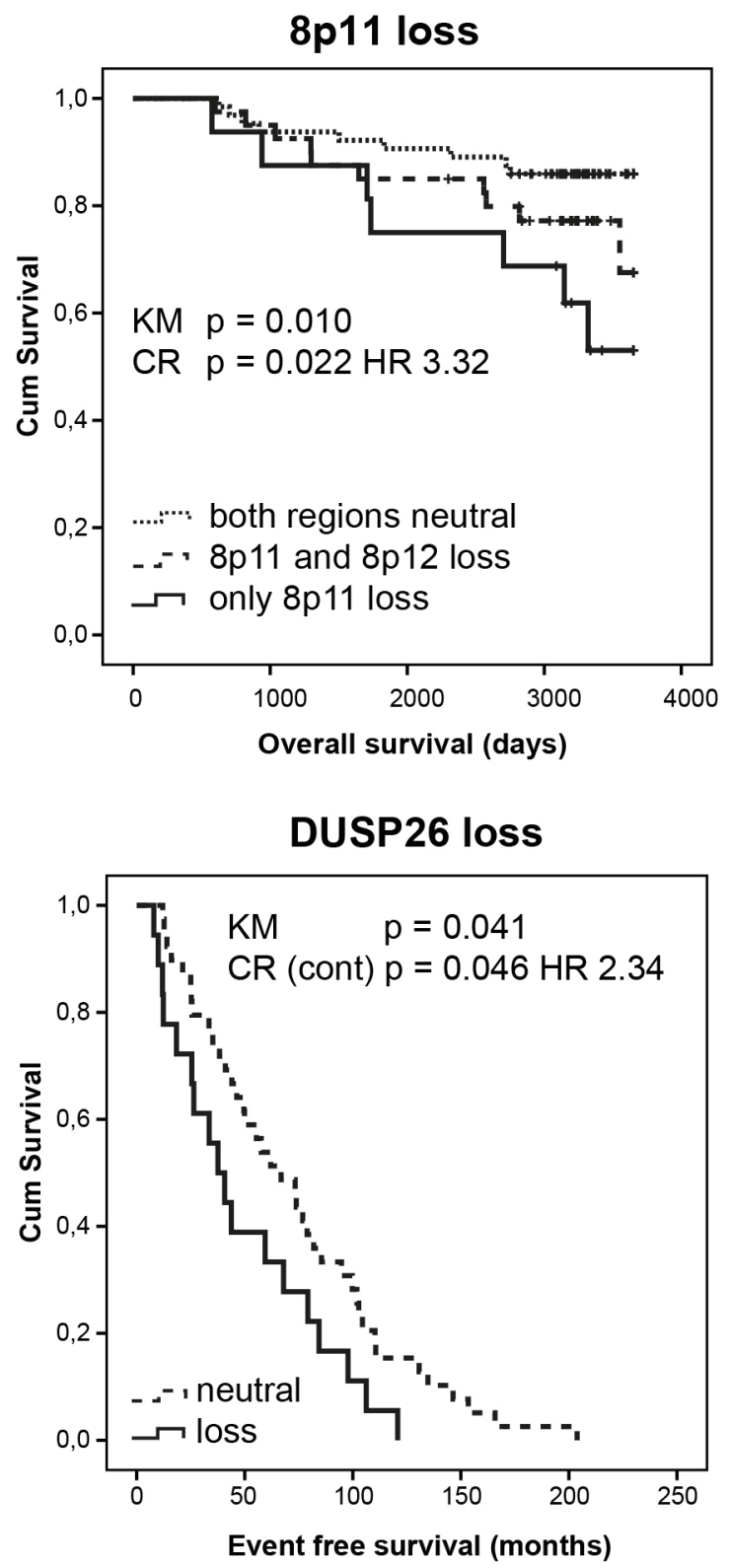

WRN loss $(\mathrm{p}=0.018 ;$ HR 1.40), UNC5D loss $(\mathrm{p}=0.017$; HR 1.43), ZNF703 loss ( $\mathrm{p}=0.023$; HR 1.47), FGFR1 loss $(\mathrm{p}=0.002$; HR 1.70) or amplification $(\mathrm{p}=0.083$; HR 1.36), PRKDC loss ( $\mathrm{p}=0.045$; HR 1.74), a loss of at least 2 genes of NRG1, DUSP26 and UNC5D ( $\mathrm{p}=0.016$; HR 1.38; 95\% CI 1.06-1.80) and LOH at $8 \mathrm{p}(\mathrm{p}=0.021$; HR $1.36 ; 95 \%$ CI 1.05-1.76) predicted worse DFS in HT-treated patients but not in HT-naïve patients, suggesting a correlation with HT resistance. Loss at 8p11 and especially loss at 8p11 without adjacent $8 \mathrm{p} 12$ loss were independent predictors of poor DFS in HT-naïve patients only $(\mathrm{p}=0.035$; HR 1.481 and $p=0.000$; HR 7.123, respectively). Amplification at 8 p11 was also independently indicative of worse DFS in
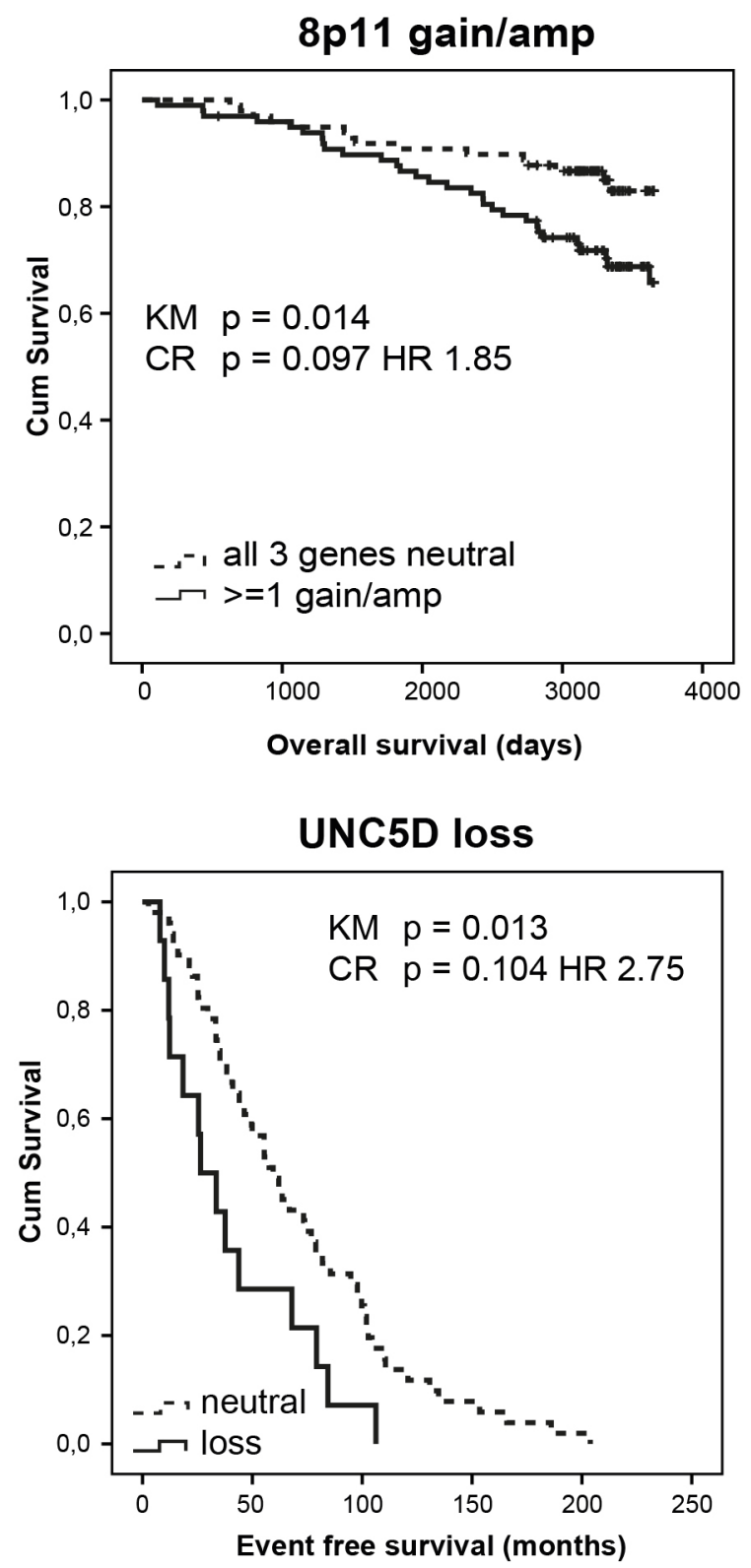

Figure 1: Allelic loss and gain/amplification at 8p11 independently predict poor overall survival in a set of 234 female breast tumors analysed by MLPA. DUSP 26 and UNC5D copy number loss independently predict worse event free survival. KM = Kaplan Meier analysis; $\mathrm{CR}=\mathrm{Cox}$ Regression analysis; $\mathrm{HR}=$ hazard ratio. 
CT/HT/RT treatment-naïve patients. As compared with our dataset, METABRIC confirmed 8p12 gain as a predictor of CT sensitivity (Figure 3), FNTA amplification as a predictor of CT resistance, (focal) 8p11 loss/amplification as a strong independent predictor of poor prognosis in HTnaïve patients, and LOH in the NRG1/DUSP26/UNC5D breakpoint region as a predictor of RT resistance.

\section{Correlation between copy number loss, mRNA expression and survival in METABRIC}

WRN $(\mathrm{p}=1 \mathrm{E}-13)$, ZNF703 $(\mathrm{p}=2 \mathrm{E}-9), \quad F G F R 1$ $(\mathrm{p}=1 \mathrm{E}-10), F N T A(\mathrm{p}=1 \mathrm{E}-13)$ and PRKDC $(\mathrm{p}=1 \mathrm{E}-13)$
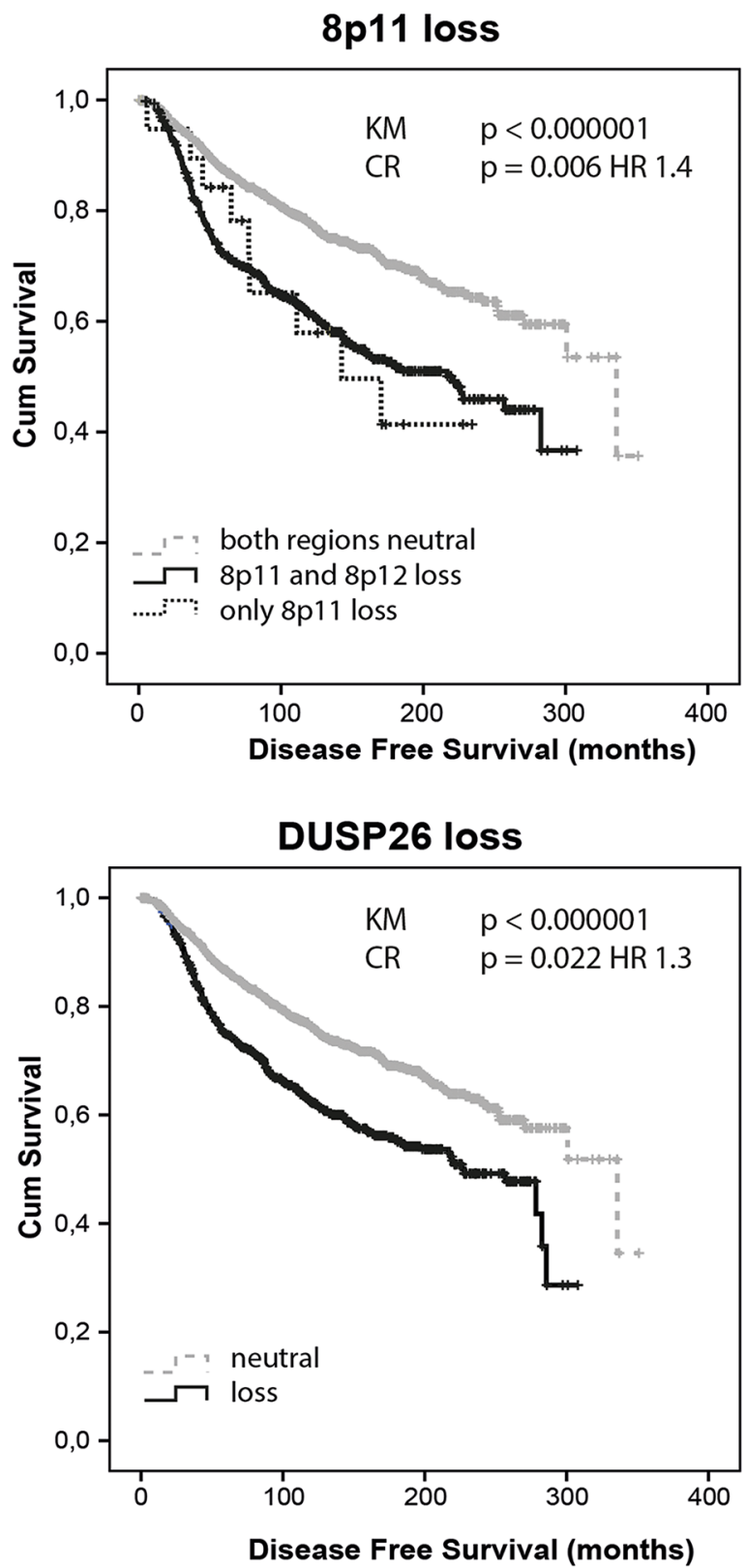

demonstrated a significant correlation between copy number loss and mRNA expression downregulation (Supplementary Figure 4). All interrogated genes demonstrated a significant correlation between copy number gain and mRNA upregulation $(W R N \mathrm{p}=1 \mathrm{E}-13$; NRG1 $\mathrm{p}=0.016$; DUSP26 $\mathrm{p}=0.004 ;$ UNC5D $\mathrm{p}=0.042$; ZNF703 p=1E-13; FGFR1 p=1E-13; FNTA $\mathrm{p}=1 \mathrm{E}-13$ and $P R K D C \mathrm{p}=1 \mathrm{E}-13)$. mRNA expression of $N R G 1$, DUSP26 and UNC5D was low (median $\mathrm{Z}$ score $<$ $0)$ regardless of the copy number status, suggesting that alternative mechanisms such as DNA promoter hypermethylation may play a more important role here. The Kaplan Meier Plotter (http://kmplot.com/analysis/)
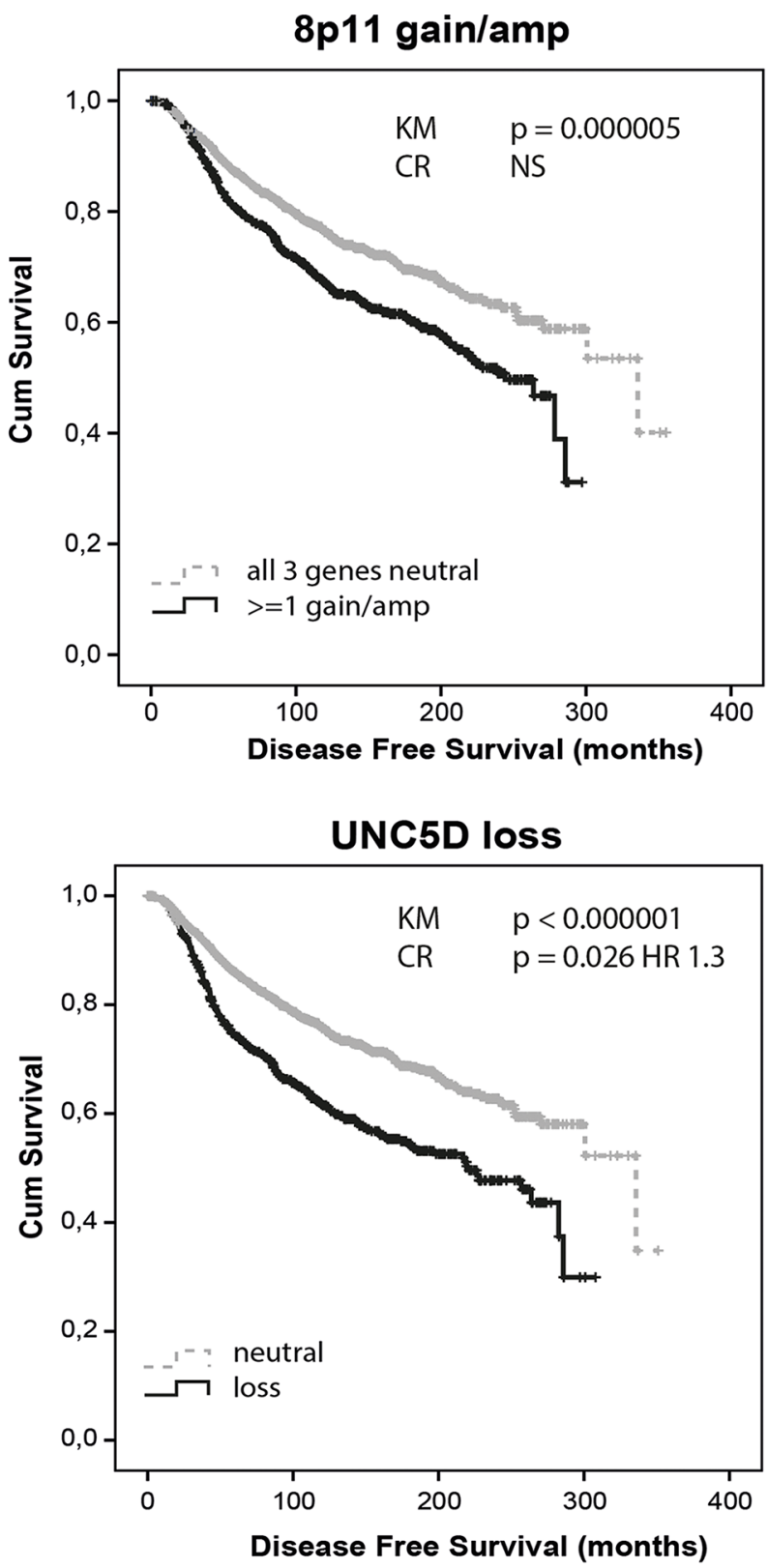

Figure 2: Allelic loss and gain/amplification at 8 p11 predict poor disease free survival in METABRIC. $D U S P 26$ and UNC5D copy number loss independently predict worse disease free survival. $\mathrm{KM}=$ Kaplan Meier analysis; $\mathrm{CR}=\mathrm{Cox}$ Regression analysis . 
was used to determine the relationship between mRNA expression and relapse free survival in 3951 breast cancer samples [31]. For WRN ( $\mathrm{p}=1.1 \mathrm{E}-08$; HR 0.73, 95\% CI 0.65-0.81), NRG1 ( $\mathrm{p}=7.3 \mathrm{E}-07$; HR 0.74, 95\% CI 0.66-0.84), DUSP26 ( $\mathrm{p}=2.6 \mathrm{E}-08$; HR $0.73,95 \%$ CI 0.66-0.82), UNC5D ( $\mathrm{p}=0.00085$; HR $0.76,95 \%$ CI 0.65-0.9) and FGFR1 ( $\mathrm{p}=3.3 \mathrm{E}-8$; HR 0.63, 95\% CI 0.53-0.74), mRNA downregulation predicted worse relapse free survival (Figure 4). In contrast, for FNTA $(\mathrm{p}=1.2 \mathrm{E}-07$; HR 1.36; 95\% CI 1.22-1.53) and PRKDC $(p=4.9 E-08 ;$ HR 1.38; 95\% CI 1.23-1.56), a mRNA upregulation predicted worse survival. For ZNF703, no data were available.
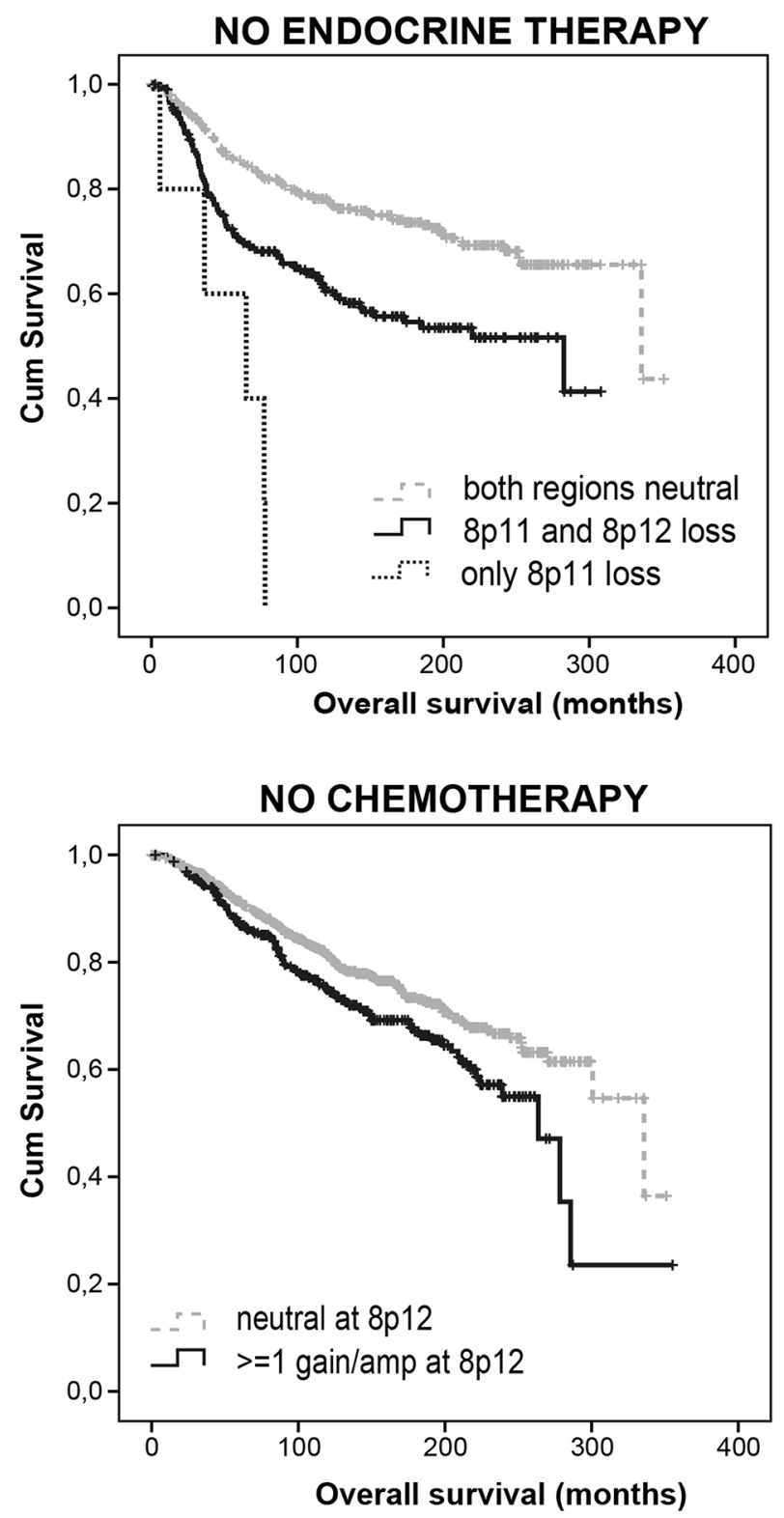

\section{DISCUSSION}

The 8p11-12 genomic region is characterized by a strong $4 \mathrm{MB}$ putative breakpoint region between $Z N F 703$ (37553269 bp from pter) and DUSP26 (33448851 bp from pter). This study investigated the clinical relevance of copy number alterations in the 8p11-12 breakpoint region in breast cancer. We have shown and confirmed by METABRIC that both gain/amplification and loss in this region correlate with a more aggressive tumor phenotype. The presence of at least one highlevel amplification at 8p11-12, in particular FGFR1 amplification, was an independent predictor of poor
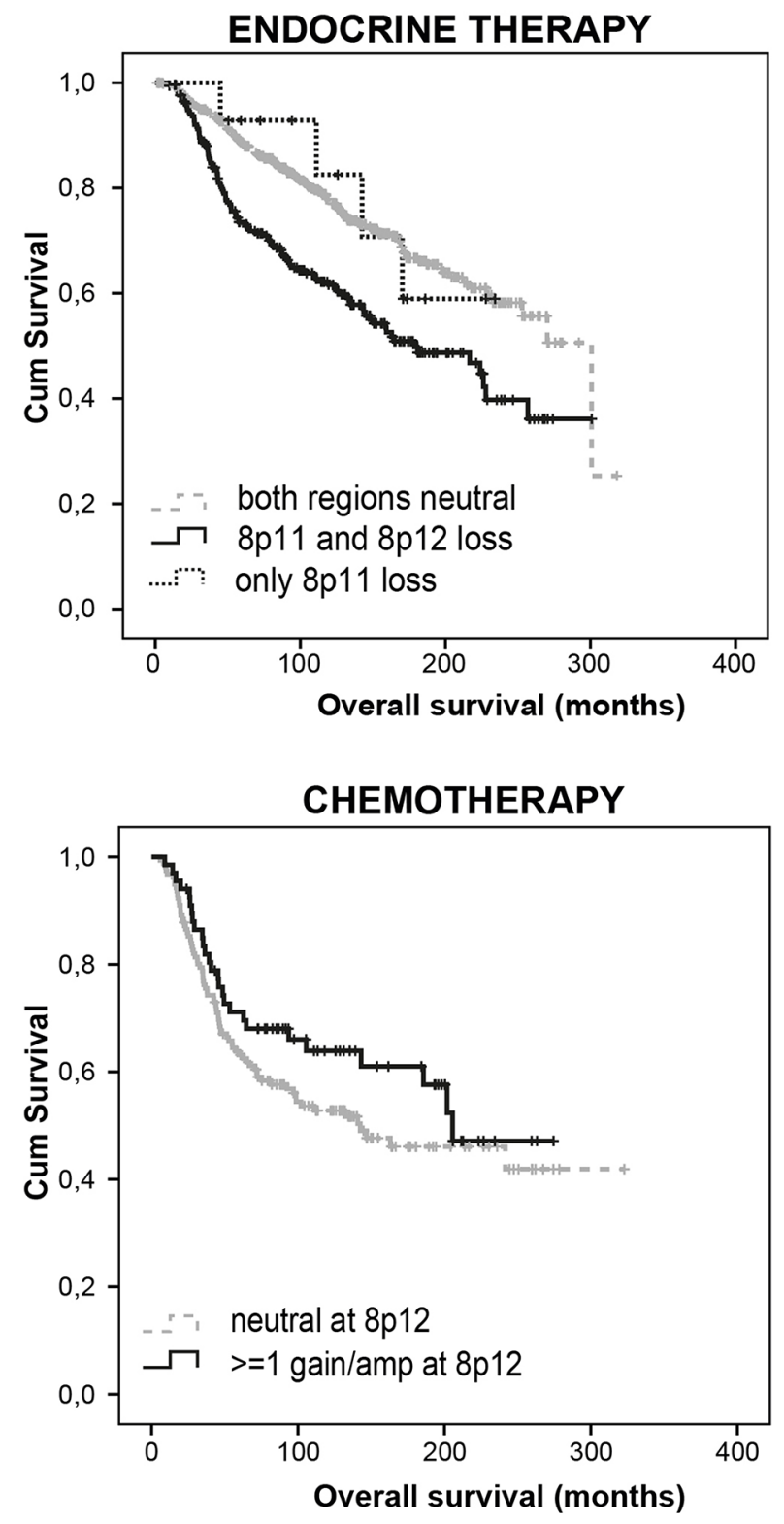

Figure 3: Loss at 8p11 predicts poor prognosis, particularly in endocrine treatment naïve patients, while gain at $8 p 12$ predicts chemotherapy sensitivity. Figure based on METABRIC data. 
survival in both datasets. Interestingly, although it has long been assumed that copy number loss at the FGFR1containing $8 \mathrm{p} 11$ region is a bystander effect of deletions occurring more distal on chromosome 8p12, 8p11 loss was an independent predictor of poor OS in both datasets, even without adjacent 8p12 loss. Although copy number increase at the 8 p11 region was independently correlated with worse OS in our dataset, this association was secondary to other tumor characteristics in METABRIC. Additionally, loss of DUSP26 and UNC5D, located in the 8 p12 breakpoint region, independently predicted worse survival. Interestingly, in both datasets, allelic loss at 8p12 was associated with worse EFS or DFS within the luminal A(-like) subtype, suggesting a prognostic role of $8 \mathrm{p}$ copy number alterations within this subtype as well. In glioblastoma, DUSP26 mRNA expression is downregulated and plays a role in intracellular transport and cell-cell adhesion [23]. In epithelial cells, DUSP26 negatively affects proliferation [24] and interacts with/ is activated by adenylate kinase 2 (AK2). This complex is able to dephosphorylate fas-associated protein with death domain (FADD) to downregulate cell growth [25]. On the other hand, DUSP26 seems to have oncogenic as well as tumor suppressor characteristics. In thyroid cancer, for example, DUSP26 is amplified and promotes cell growth by inhibiting the p38 MAPK activity [26]. UNC5D, a netrin receptor involved in apoptosis, was described as tumor suppressor gene in renal cell carcinoma [27] and bladder cancer [28], and was shown to reside in a genetic locus predisposing to colon carcinoma in mice [29].

Gains/amplifications in the $8 \mathrm{p} 12$ region encompassing $W R N, N R G 1, D U S P 26$ and UNC5D, were seen in $20-30 \%$ of patients, were indicative of higher mRNA expression levels and independently predicted CT sensitivity. Losses at 8p12 independently predicted RT resistance but for most genes located in this region, mRNA expression levels were low regardless of copy number levels suggesting alternative regulatory mechanisms such as promoter hypermethylation. In line with these observations, DUSP26 functions as a p53 phosphatase [30] and UNC5D as a p53 target gene [31]. Both genes may therefore modulate chemo- and radiotherapy response. Overexpression of DUSP26 was shown to sensitize PC12 cells to cisplatin-induced apoptosis [32]. Furthermore, DUSP 26 mRNA expression was enhanced by treatment of ovarian cancer cell lines with 5-aza-2-deoxycytidine (demethylation) and trichostatin A (HDAC inhibitor) [24]. In bladder cancer and neuroblastoma cell lines, UNC5D knockdown decreased sensitivity to cisplatin, mediated through E2F1, p53 and DAPK [28, 31, 33]. In addition, histone deacetylase and methylation inhibitors were able to restore UNC5D expression [27, 33]. Our study did observe an association between DUSP26 and UNC5D loss and $\mathrm{CT}$ resistance, but we were not able to confirm this


Figure 4: Association between WRN, NRG1, DUSP26, UNC5D, FGFR1 and FNTA mRNA expression levels and relapse free survival (KMplotter). 
finding in METABRIC. Also located at $8 \mathrm{p} 12$ is $N R G 1$. The neuregulin-1 gene has been proposed both as a candidate oncogene [34] and as a candidate tumor suppressor gene [35]. It encodes ligands that bind the ERBB/HER family of receptors (ERBB3/4) [35]. Although the NRG1-encoded proteins are usually thought of as mitogens, they can also be pro-apoptotic upon forced expression [36]. Elevated NRG1 expression in tumors lacking HER2 amplification is strongly associated with lapatinib sensitivity in vitro [37]. Chua et al. reported significant NRG1 methylation in breast cancer cell lines and demonstrated that, after treatment with aza-deoxycitidine, the transcription of $N R G 1$ was activated. In addition, NRG1 was identified as one of 15 breast cancer anti-estrogen resistance genes [38]. The fourth gene interrogated at 8p12 was WRN, a member of the RecQ family of DNA helicases that possesses a 3'-5'exonuclease activity. The main functions of WRN are in DNA repair and in telomere maintenance. WRN expression may play a role in chemoradiotherapy response by limiting DNA damage and replicative stress and thus preventing senescence [39-41]. Colorectal tumors lacking WRN have been shown to be more sensitive to topoisomerase I inhibitors and DNA-damaging agents, as conversion of treatment-induced single strand breaks into double strand breaks occurs at a high frequency in absence of WRN $[42,43]$.

Loss in the 8p11 region (ZNF703,FGFR1 and $F N T A$ ) was seen in about $25 \%$ of patients, correlated with lower mRNA expression levels and independently predicted poor survival, particularly in treatment-naïve patients. Although amplifications of FGFR1 and ZNF703 have been extensively investigated in line with their roles as a proto-oncogenes and predictors of endocrine therapy resistance [44-50], allelic loss of these genes has only scarcely been described. Copy number loss at $8 \mathrm{p} 11$, encompassing FGFR1 and ZNF703, was associated with ER/PR negativity and a non-luminal A-like phenotype. Our data pointed towards an association with triple negativity while METABRIC suggested an association with a HER2-driven or luminal B-like phenotype.

Copy number increase in the $8 \mathrm{p} 11$ region correlated with higher mRNA expression levels and was an independent predictor of worse OS in our dataset. Nevertheless, in METABRIC, the association with survival was secondary to other tumor/patient characteristics. Amplification of FNTA was however associated with CT resistance in both datasets. Disagreement between our and METABRIC's findings might be related to differences in cohort characteristics. For example, compared to our cohort, METABRIC contains generally older patients, fewer T1 and more poorly differentiated tumors, and more CT/RT-naïve patients. FISH analysis demonstrated that the majority of FGFR 1 copy number alterations at 8p11 were not a consequence of complete polysomy or monosomy of chromosome 8 but probably the result of focal deletions/ amplifications. This is in line with MLPA data showing only few patients with complete $8 \mathrm{p} 12$ and $8 \mathrm{p} 11$ loss or amplification.

Why cancer cells select for amplifications in some settings and copy number loss in others, is likely context dependent. Many of the interrogated genes have been described as oncogenes as well as tumor suppressor genes, with opposite roles in different cancer types and even different roles during tumor progression. This intriguing contrast complicates development of new treatment strategies. Future studies are thus needed to investigate whether gain or loss at 8p11-12 justifies heavier or adjusted treatment schedules, or may be associated with other genetic or epigenetic changes that are directly targetable.

In conclusion, we have demonstrated that gain and amplification but also loss in the 8p11-12 region correlate with a more aggressive breast cancer phenotype. Assessment of 8p11-12 gene copy number status seems to augment existing prognostic and predictive tools, and deserves to be wider studied in prospective clinical studies.

\section{MATERIALS AND METHODS}

\section{Tissue selection and DNA isolation}

244 formalin fixed paraffin embedded female primary breast cancer specimens were obtained from the archives of the Department of Pathology of the University Medical Center Utrecht, The Netherlands. For all patients, clinical follow-up (mean/median followup of approximately 8 years) was available from the Netherlands Cancer Registry (NCR) and pathological characteristics were extracted from the nationwide network and registry of histo- and cytopathology in the Netherlands (PALGA). Use of anonymous or coded 'left over' material for scientific purposes does not require informed consent according to Dutch legislation (Medical Research Involving Human Subjects Act) and therefore obtains exempt from our institutional medical ethical review board [51].

Prior to DNA extraction, hematoxylin-eosin stained slides were reviewed by an experienced pathologist (PvD) to confirm the presence of malignancy. All samples were estimated to have a tumor percentage of at least $60 \%$. Areas with lymphocytic infiltrate or ductal carcinoma in situ were avoided. Tumor tissue was scraped off from the marked tumor area on four $4 \mu \mathrm{m}$ thick paraffin sections, and incubated overnight in proteinase $\mathrm{K}(10 \mathrm{mg} / \mathrm{ml}$; Roche, Almere, The Netherlands) at $56^{\circ} \mathrm{C}$ followed by heat inactivation, centrifugation and recovery of the supernatant.

\section{Multiplex ligation-dependent probe amplification}

MLPA was performed according to the manufacturer's (MRC Holland, Amsterdam, The Netherlands) instructions 
using the SALSA MLPA Breast Tumor probemix P078-C1 [52-54] for FGFR1, and a custom synthetic MLPA kit containing 11 probes against WRN (2 probes), NRG1 (2 probes), DUSP26 (2 probes), UNC5D (2 probes), ZNF703 (1 probe), FNTA (1 probe) and PRKDC (1 probe; on $8 \mathrm{q})$. For the latter, probes were mixed with the SALSA P200-A1 MLPA reference probemix, containing 11 reference probes for normalisation. Supplementary Table 1 shows the locations and partial sequences of the chromosome 8 probes in both probemixes. For genes with more than one probe present, the arithmetic mean of all the probe peaks of this gene in duplicate was calculated. Cut-offs for loss and copy number increase (gain or amplification) were determined per gene, based on the minimum and maximum ratio values of normal breast tissue taken along each MLPA run (Table 1). Amplification was defined as an MLPA ratio larger than 2.0. PCR was performed on 244 tumors, of which 5 samples were excluded from the custom MLPA kit, $(\mathrm{n}=239)$ and 10 samples from the P078-C1 MLPA kit based on quality assessment $(n=234)$. Paired data were available for 234 tumors. Supplementary Table 2 shows basic clinical and pathological characteristics of the patients and primary tumors studied. All data generated or analysed during this study are included in this published article and its supplementary information files.

\section{METABRIC data extraction}

METABRIC clinical data and copy number alteration (CNA) and mRNA Expression z-Scores (U133 microarray) from chromosome 8 were downloaded via The cBioPortal for Cancer Genomics $[55,56]$. Putative gene copy number calls from DNA copy were used to extract amplification and deletion status and to create a chromosome 8 heatmap. Supplementary Table 3 shows basic clinical and pathological characteristics of METABRIC patients and primary tumors studied. Mean and median follow-up was 10.4 years and 9.7 years, respectively.

\section{Fluorescence in situ hybridisation}

FISH was performed on TMA sections (containing a subset of 217 tumors) using a three-colour FGFR1 Breakapart/Amplification probe (Cytocell, LPS 018). A detailed description of the FISH procedure can be found in Supplementary Methods. Based on comparison with MLPA, we defined an FGFRl copy number lower than 1.34 as loss, and higher than 3.17 as gain or amplification.

\section{Statistical analysis}

Breast tumors were classified into Luminal A (ER+ and/or PR+, HER2-, mitotic activity index (MAI) $\leq 14)$, luminal $\mathrm{B}(\mathrm{ER}+$ and/or PR+ and (HER2+ or MAI $>14)$ ), HER2 driven (ER-, PR-, HER2+) and triple negative (ER-, PR-, HER2-) subtypes. The MAI was determined by examining stained slides of tumor and counting the number of visible mitotic figures in the area containing the highest density of mitotic figures. The total number of mitotic figures counted in an area of $2 \mathrm{~mm} 2$ is the MAI. The variables ER $(>10 \%)$, PR $(>10 \%)$, HER2 $(3+)$, MAI $(>14)$, tumor size $(>\mathrm{T} 1)$, lymph node status (positive vs. negative), age $(>50)$, and grade using the Nottingham Histologic Score system (the Elston-Ellis modification of Scarff-Bloom-Richardson grading system, 3 vs 1/2) were categorized for Chi Square statistics.

MLPA gene copy number data were grouped as loss, neutral, gain/amplification or amplification. In addition, four genomic sub-regions were investigated for the presence of copy number alterations and their associations with classical pathological characteristics: the $8 \mathrm{p} 12$ region (WRN, NRG1, DUSP26 and UNC5D), the 8p11 region (ZNF703, FGFR1 and FNTA) and the combination of both these regions (defined as 8p11-12).

The Mann-Whitney test was used to evaluate the association between copy number alterations (versus neutral copy number) and mRNA expression z-scores by METABRIC. Overall survival (OS), event free survival (EFS; event = recurrence or metastasis), and disease free survival (DFS; METABRIC) curves were constructed using the Kaplan-Meier method and the log-rank test was used to test for significance. Multivariate survival analysis was performed using a backward Cox proportional hazards model. Characteristics with a $\mathrm{p}<.10$ in univariate analysis and potential confounders were included.

All statistical analyses were conducted with IBM SPSS 21 statistical software, regarding two-sided p-values below 0.05 as significant. For survival, at least 5 non-censored events in each category were required for consideration.

\section{Author contributions}

CBM and CMGvM were involved in data acquisition and analysis, and CBM in interpretation of data and drafting the article. EvdW and PJvD made substantial contributions to conception and design. All authors were involved in writing the paper and had final approval of the submitted and published versions.

\section{ACKNOWLEDGMENTS}

We would like to acknowledge METABRIC for making their information open for public through the cBioPortal for cancer genomics.

\section{CONFLICTS OF INTEREST}

The authors declare no conflicts of interest.

\section{FUNDING}

There are no funding sources to declare. 


\section{REFERENCES}

1. Hurst CD, Fiegler H, Carr P, Williams S, Carter NP, Knowles MA. High-resolution analysis of genomic copy number alterations in bladder cancer by microarray-based comparative genomic hybridization. Oncogene. 2004; 23:2250-63.

2. Hwang ES, DeVries S, Chew KL, Moore DH 2nd, Kerlikowske K, Thor A, Ljung BM, Waldman FM. Patterns of chromosomal alterations in breast ductal carcinoma in situ. Clin Cancer Res. 2004; 10:5160-7.

3. Ohata H, Emi M, Fujiwara Y, Higashino K, Nakagawa K, Futagami R, Tsuchiya E, Nakamura Y. Deletion mapping of the short arm of chromosome 8 in non-small cell lung carcinoma. Genes Chromosomes Cancer. 1993; 7:85-8.

4. Emi M, Fujiwara Y, Nakajima T, Tsuchiya E, Tsuda H, Hirohashi S, Maeda Y, Tsuruta K, Miyaki M, Nakamura Y. Frequent loss of heterozygosity for loci on chromosome $8 \mathrm{p}$ in hepatocellular carcinoma, colorectal cancer, and lung cancer. Cancer Res. 1992; 52:5368-72.

5. Gelsi-Boyer V, Orsetti B, Cervera N, Finetti P, Sircoulomb F, Rouge C, Lasorsa L, Letessier A, Ginestier C, Monville F, Esteyriès S, Adélaïde J, Esterni B, et al. Comprehensive profiling of 8p11-12 amplification in breast cancer. Mol Cancer Res. 2005; 3:655-67.

6. Brown MR, Chuaqui R, Vocke CD, Berchuck A, Middleton LP, Emmert-Buck MR, Kohn EC. Allelic loss on chromosome arm 8p: analysis of sporadic epithelial ovarian tumors. Gynecol Oncol. 1999; 74:98-102.

7. Vocke CD, Pozzatti RO, Bostwick DG, Florence CD, Jennings SB, Strup SE, Duray PH, Liotta LA, EmmertBuck MR, Linehan WM. Analysis of 99 microdissected prostate carcinomas reveals a high frequency of allelic loss on chromosome 8p12-21. Cancer Res. 1996; 56:2411-6.

8. Bova GS, Carter BS, Bussemakers MJ, Emi M, Fujiwara Y, Kyprianou N, Jacobs SC, Robinson JC, Epstein JI, Walsh PC, Isaacs WB. Homozygous deletion and frequent allelic loss of chromosome 8p22 loci in human prostate cancer. Cancer Res. 1993; 53:3869-73.

9. Yaremko ML, Recant WM, Westbrook CA. Loss of heterozygosity from the short arm of chromosome 8 is an early event in breast cancers. Genes Chromosomes Cancer. 1995; 13:186-91.

10. Lebok P, Mittenzwei A, Kluth M, Ozden C, Taskin B, Hussein K, Möller K, Hartmann A, Lebeau A, Witzel I, Mahner S, Wölber L, Jänicke F, et al. 8p deletion is strongly linked to poor prognosis in breast cancer. Cancer Biol Ther. 2015; 16:1080-7.

11. Utada Y, Haga S, Kajiwara T, Kasumi F, Sakamoto G, Nakamura Y, Emi M. Allelic loss at the 8p22 region as a prognostic factor in large and estrogen receptor negative breast carcinomas. Cancer. 2000; 88:1410-6.

12. Yokota T, Yoshimoto M, Akiyama F, Sakamoto G, Kasumi F, Nakamura Y, Emi M. Localization of a tumor suppressor gene associated with the progression of human breast carcinoma within a 1-cM interval of 8p22-p23.1. Cancer. 1999; 85:447-52.

13. Armes JE, Hammet F, de Silva M, Ciciulla J, Ramus SJ, Soo WK, Mahoney A, Yarovaya N, Henderson MA, Gish K, Hutchins AM, Price GR, Venter DJ. Candidate tumorsuppressor genes on chromosome arm $8 \mathrm{p}$ in early-onset and high-grade breast cancers. Oncogene. 2004; 23:5697-702.

14. Cai Y, Crowther J, Pastor T, Abbasi Asbagh L, Baietti MF, De Troyer M, Vazquez I, Talebi A, Renzi F, Dehairs J, Swinnen JV, Sablina AA. Loss of chromosome $8 \mathrm{p}$ governs tumor progression and drug response by altering lipid metabolism. Cancer Cell. 2016; 29:751-66.

15. Emi M, Fujiwara Y, Ohata H, Tsuda H, Hirohashi S, Koike M, Miyaki M, Monden M, Nakamura Y. Allelic loss at chromosome band 8p21.3-p22 is associated with progression of hepatocellular carcinoma. Genes Chromosomes Cancer. 1993; 7:152-7.

16. Fujiwara Y, Emi M, Ohata H, Kato Y, Nakajima T, Mori T, Nakamura Y. Evidence for the presence of two tumor suppressor genes on chromosome $8 \mathrm{p}$ for colorectal carcinoma. Cancer Res. 1993; 53:1172-4.

17. Knowles MA, Shaw ME, Proctor AJ. Deletion mapping of chromosome 8 in cancers of the urinary bladder using restriction fragment length polymorphisms and microsatellite polymorphisms. Oncogene. 1993; 8:1357-64.

18. Suzuki H, Emi M, Komiya A, Fujiwara Y, Yatani R, Nakamura Y, Shimazaki J. Localization of a tumor suppressor gene associated with progression of human prostate cancer within a $1.2 \mathrm{mb}$ region of 8p22-p21.3. Genes Chromosomes Cancer. 1995; 13:168-74.

19. Kluth M, Amschler NN, Galal R, Moller-Koop C, Barrow P, Tsourlakis MC, Jacobsen F, Hinsch A, Wittmer C, Steurer $\mathrm{S}$, Krech T, Büscheck F, Clauditz TS, et al. Deletion of $8 \mathrm{p}$ is an independent prognostic parameter in prostate cancer. Oncotarget. 2017; 8:379-92. https://doi.org./10.18632/ oncotarget. 13425 .

20. Reis-Filho JS, Simpson PT, Turner NC, Lambros MB, Jones C, Mackay A, Grigoriadis A, Sarrio D, Savage K, Dexter T, Iravani M, Fenwick K, Weber B, et al. FGFR1 emerges as a potential therapeutic target for lobular breast carcinomas. Clin Cancer Res. 2006; 12:6652-62.

21. Pole JC, Courtay-Cahen C, Garcia MJ, Blood KA, Cooke SL, Alsop AE, Tse DM, Caldas C, Edwards PA. Highresolution analysis of chromosome rearrangements on $8 p$ in breast, colon and pancreatic cancer reveals a complex pattern of loss, gain and translocation. Oncogene. 2006; 25:5693-706.

22. Coquelle A, Pipiras E, Toledo F, Buttin G, Debatisse M. Expression of fragile sites triggers intrachromosomal mammalian gene amplification and sets boundaries to early amplicons. Cell. 1997; 89:215-25.

23. Tanuma N, Nomura M, Ikeda M, Kasugai I, Tsubaki Y, Takagaki K, Kawamura T, Yamashita Y, Sato I, Sato M, 
Katakura R, Kikuchi K, Shima H. Protein phosphatase dusp26 associates with KIF3 motor and promotes $\mathrm{N}$-cadherin-mediated cell-cell adhesion. Oncogene. 2009; 28:752-61.

24. Patterson KI, Brummer T, Daly RJ, O'Brien PM. DUSP26 negatively affects the proliferation of epithelial cells, an effect not mediated by dephosphorylation of MAPKs. Biochim Biophys Acta. 2010; 1803:1003-12.

25. Kim H, Lee HJ, Oh Y, Choi SG, Hong SH, Kim HJ, Lee SY, Choi JW, Su Hwang D, Kim KS, Kim HJ, Zhang J, Youn HJ, et al. The DUSP26 phosphatase activator adenylate kinase 2 regulates FADD phosphorylation and cell growth. Nat Commun. 2014; 5:3351.

26. Yu W, Imoto I, Inoue J, Onda M, Emi M, Inazawa J. A novel amplification target, DUSP26, promotes anaplastic thyroid cancer cell growth by inhibiting p38 MAPK activity. Oncogene. 2007; 26:1178-87.

27. Lu D, Dong D, Zhou Y, Lu M, Pang XW, Li Y, Tian XJ, Zhang Y, Zhang J. The tumor-suppressive function of UNC5D and its repressed expression in renal cell carcinoma. Clin Cancer Res. 2013; 19:2883-92.

28. Zhu Y, Yu M, Chen Y, Wang Y, Wang J, Yang C, Bi J. Down-regulation of UNC5D in bladder cancer: UNC5D as a possible mediator of cisplatin induced apoptosis in bladder cancer cells. J Urol. 2014; 192:575-82.

29. Liu P, Lu Y, Liu H, Wen W, Jia D, Wang Y, You M. Genome-wide association and fine mapping of genetic loci predisposing to colon carcinogenesis in mice. Mol Cancer Res. 2012; 10:66-74.

30. Shang X, Vasudevan SA, Yu Y, Ge N, Ludwig AD, Wesson CL, Wang K, Burlingame SM, Zhao YJ, Rao PH, Lu X, Russell HV, Okcu MF, et al. Dual-specificity phosphatase 26 is a novel p53 phosphatase and inhibits p53 tumor suppressor functions in human neuroblastoma. Oncogene. 2010; 29:4938-46.

31. Wang H, Wu Q, Li S, Zhang B, Chi Z, Hao L. Unc5D regulates p53-dependent apoptosis in neuroblastoma cells. Mol Med Rep. 2014; 9:2411-6.

32. Wang JY, Lin $\mathrm{CH}$, Yang $\mathrm{CH}$, Tan $\mathrm{TH}$, Chen YR. Biochemical and biological characterization of a neuroendocrine-associated phosphatase. J Neurochem. 2006; 98:89-101.

33. Zhu Y, Li Y, Haraguchi S, Yu M, Ohira M, Ozaki T, Nakagawa A, Ushijima T, Isogai E, Koseki H, Nakamura $\mathrm{Y}$, Kong C, Mehlen $\mathrm{P}$, et al. Dependence receptor UNC5D mediates nerve growth factor depletioninduced neuroblastoma regression. J Clin Invest. 2013; 123:2935-47.

34. Haskins JW, Nguyen DX, Stern DF. Neuregulin 1-activated ERBB4 interacts with YAP to induce Hippo pathway target genes and promote cell migration. Sci Signal. 2014; 7:ra116.

35. Chua YL, Ito Y, Pole JC, Newman S, Chin SF, Stein RC, Ellis IO, Caldas C, O'Hare MJ, Murrell A, Edwards PA.
The NRG1 gene is frequently silenced by methylation in breast cancers and is a strong candidate for the $8 \mathrm{p}$ tumour suppressor gene. Oncogene. 2009; 28:4041-52.

36. Weinstein EJ, Grimm S, Leder P. The oncogene heregulin induces apoptosis in breast epithelial cells and tumors. Oncogene. 1998; 17:2107-13.

37. Wilson TR, Lee DY, Berry L, Shames DS, Settleman J. Neuregulin-1-mediated autocrine signaling underlies sensitivity to HER2 kinase inhibitors in a subset of human cancers. Cancer Cell. 2011; 20:158-72.

38. van Agthoven T, Sieuwerts AM, Meijer D, Meijer-van Gelder ME, van Agthoven TL, Sarwari R, Sleijfer S, Foekens JA, Dorssers LC. Selective recruitment of breast cancer anti-estrogen resistance genes and relevance for breast cancer progression and tamoxifen therapy response. Endocr Relat Cancer. 2010; 17:215-30.

39. Kulawiec M, Safina A, Desouki MM, Still I, Matsui S, Bakin A, Singh KK. Tumorigenic transformation of human breast epithelial cells induced by mitochondrial DNA depletion. Cancer Biol Ther. 2008; 7:1732-43.

40. Opresko PL. Telomere ResQue and preservation--roles for the werner syndrome protein and other RecQ helicases. Mech Ageing Dev. 2008; 129:79-90.

41. Lee SJ, Lee SH, Ha NC, Park BJ. Estrogen prevents senescence through induction of WRN, Werner syndrome protein. Horm Res Paediatr. 2010; 74:33-40.

42. Agrelo R, Cheng WH, Setien F, Ropero S, Espada J, Fraga MF, Herranz M, Paz MF, Sanchez-Cespedes M, Artiga MJ, Guerrero D, Castells A, von Kobbe C, et al. Epigenetic inactivation of the premature aging Werner syndrome gene in human cancer. Proc Natl Acad Sci U S A. 2006; 103:8822-7.

43. Christmann M, Tomicic MT, Gestrich C, Roos WP, Bohr VA, Kaina B. WRN protects against topo I but not topo II inhibitors by preventing DNA break formation. DNA Repair (Amst). 2008; 7:1999-2009.

44. Andre F, Job B, Dessen P, Tordai A, Michiels S, Liedtke C, Richon C, Yan K, Wang B, Vassal G, Delaloge S, Hortobagyi GN, Symmans WF, et al. Molecular characterization of breast cancer with high-resolution oligonucleotide comparative genomic hybridization array. Clin Cancer Res. 2009; 15:441-51.

45. Andre F, Bachelot T, Campone M, Dalenc F, Perez-Garcia JM, Hurvitz SA, Turner N, Rugo H, Smith JW, Deudon S, Shi M, Zhang Y, Kay A. Targeting FGFR with dovitinib (TKI258): Preclinical and clinical data in breast cancer. Clin Cancer Res. 2013; 19:3693-702.

46. Andre F, Bachelot T, Commo F, Campone M, Arnedos M, Dieras V, Lacroix-Triki M, Lacroix L, Cohen P, Gentien D, Adélaide J, Dalenc F, Goncalves A, et al. Comparative genomic hybridisation array and DNA sequencing to direct treatment of metastatic breast cancer: a multicentre, prospective trial (SAFIR01/UNICANCER). Lancet Oncol. $2014 ; 15: 267-74$. 
47. Turner N, Pearson A, Sharpe R, Lambros M, Geyer F, Lopez-Garcia MA, Natrajan R, Marchio C, Iorns E, Mackay A, Gillett C, Grigoriadis A, Tutt A, et al. FGFR1 amplification drives endocrine therapy resistance and is a therapeutic target in breast cancer. Cancer Res. 2010; 70:2085-94.

48. Elbauomy Elsheikh S, Green AR, Lambros MB, Turner NC, Grainge MJ, Powe D, Ellis IO, Reis-Filho JS. FGFR1 amplification in breast carcinomas: a chromogenic in situ hybridisation analysis. Breast Cancer Res. 2007; 9:R23.

49. Spellman P, Gray J. A new treasure in the breast cancer gene hunt. Nat Med. 2011; 17:422-3.

50. Zhang X, Mu X, Huang O, Xie Z, Jiang M, Geng M, Shen K. Luminal breast cancer cell lines overexpressing ZNF703 are resistant to tamoxifen through activation of Akt/mTOR signaling. PLoS One. 2013; 8:e72053.

51. van Diest PJ. No consent should be needed for using leftover body material for scientific purposes. For. BMJ. 2002; 325:648-51.

52. Moelans CB, de Weger RA, Monsuur HN, Vijzelaar R, van Diest PJ. Molecular profiling of invasive breast cancer by multiplex ligation-dependent probe amplification-based copy number analysis of tumor suppressor and oncogenes. Mod Pathol. 2010; 23:1029-39.

53. Moelans CB, de Weger RA, van Blokland MT, van der Wall E, van Diest PJ. Simultaneous detection of TOP2A and HER2 gene amplification by multiplex ligation-dependent probe amplification in breast cancer. Mod Pathol. 2010; 23:62-70.

54. Moelans CB, de Wegers RA, Monsuurs HN, Maess AH, van Diest PJ. Molecular differences between ductal carcinoma in situ and adjacent invasive breast carcinoma: a multiplex ligation-dependent probe amplification study. Cell Oncol (Dordr). 2011; 34:475-82.

55. Cerami E, Gao J, Dogrusoz U, Gross BE, Sumer SO, Aksoy BA, Jacobsen A, Byrne CJ, Heuer ML, Larsson E, Antipin Y, Reva B, Goldberg AP, et al. The cBio cancer genomics portal: an open platform for exploring multidimensional cancer genomics data. Cancer Discov. 2012; 2:401-4.

56. Gao J, Aksoy BA, Dogrusoz U, Dresdner G, Gross B, Sumer SO, Sun Y, Jacobsen A, Sinha R, Larsson E, Cerami E, Sander C, Schultz N. Integrative analysis of complex cancer genomics and clinical profiles using the cBioPortal. Sci Signal. 2013; 6:pl1. 